\title{
AC 2008-141: SITE SPECIFIC FARMING, ENVIRONMENTAL CONCERNS, AND ASSOCIATED ADVANCED TECHNOLOGIES, PROVIDE A PLATFORM FOR ACTIVE LEARNING AND RESEARCH AT A LAND GRANT UNIVERSITY
}

\begin{abstract}
Abhijit Nagchaudhuri, University of Maryland Eastern Shore
Abhijit Nagchaudhuri is a Professor in the Department of Engineering and Aviation Sciences at University of Maryland Eastern Shore. Prior to joining UMES he worked at Turabo University in San Juan, PR as well as Duke University in Durham North Carolina as Assistant Professor and Research Assistant Professor, respectively. Dr. Nagchaudhuri is a member of ASME and ASEE professional societies and is actively involved in teaching and research in the fields of applied mechanics, robotics, systems and control and design of mechanical and mechatronic systems. Dr. Nagchaudhuri received his bachelors degree from Jadavpur University in Calcutta, India with a honors in Mechanical Engineering in 1983, thereafter, he worked in a multinational industry for 4 years before joining Tulane University as a graduate student in the fall of 1987. He received his M.S. degree from Tulane University in 1989 and Ph.D. degree from Duke University in 1992.
\end{abstract}

\section{Madhumi Mitra, University of Maryland Eastern Shore}

Madhumi Mitra is currently an Assistant Professor of Biology and Environmental Science at University of Maryland Eastern Shore. She is also the Coordinator of the Biology Education program at UMES. Dr. Mitra obtained her Ph.D. degree in 2002 from the Department of Botany at North Carolina State University. She is actively involved in research in the fields of marine biology, environmental science and paleopalynology.

Lurline Marsh, University of Maryland Eastern Shore

Dr. Lurline Marsh is a Professor and Chair of the Department of Agriculture and Resource Sciences at University of Maryland Eastern Shore.

\section{Craig Daughtry, United States Department of Agriculture}

Dr. Craig S.T. Daughtry is a Research Agronomist at USDA-ARS Hydrology and Remote Sensing Laboratory at Beltsville,Maryland. He actively collaborates with faculty at UMES on remote sensing and precision agriculture related efforts.

\section{Tracy Earle, University of Maryland Eastern Shore}

Tracy J. Earl received her Bachelors of Science in Fisheries and Wildlife Management with a dual in Animal Behavior from Michigan State University and then her Master of Science in Fisheries and Wildlife Resources from West Virginia University. She took classes in GIS, both during her Bachelors and Masters degrees. While at WVU, she used ESRI's products to work on the GAP Analysis project. After graduating, she started working at the University of Maryland Eastern Shore as a Geographic Information System Specialist. She is now the GIS Program Manager in the Dept of Agriculture at UMES.

\section{Jurgen Schwarz, University of Maryland Eastern Shore}

Dr. Jurgen G. Schwarz is an Associate Professor in the Department of Agriculture and Resource Sciences and Director for the interdisciplinary Ph.D. program in Food Science and Technology. Dr. Schwarz received his Ph.D. in Food Science and Technology from Cornell University and a Diploma in Food Engineering from the University of Hohenheim in Stuttgart, Germany. 


\title{
Site Specific Farming, Environmental Concerns, and Associated Advanced Technologies Provide a Platform for Active Learning and Research at a Land Grant University
}

\begin{abstract}
A course titled "Advanced Technologies in Agriculture and Environmental Sciences" was offered for the first time at the University of Maryland Eastern Shore in spring of 2007. The course was conceived to develop a broader student base for the "Precision Agriculture" related activities that have been ongoing at UMES for the past few years, with support from the United States Department of Agriculture (USDA) and Maryland Space Grant Consortium (MDSGC), and as such has been opened to all Science, Technology, Engineering, and Mathematics (STEM) seniors and graduate students on campus. In an effort to diffuse the compartmentalization of knowledge and rigid disciplinary boundaries within academia, the course has been designed to be a multi-instructor course. Faculty and staff from Agriculture, Natural Sciences, Engineering, Aviation Sciences, and collaborators from USDA, NASA, and representatives from a local industry involved in "Precision Farming" have worked together to plan and deliver the course. The course content spans over the fundamentals of global positioning systems (GPS), yield monitoring, soil testing, variable rate applicators, fundamentals of plant physiology and agronomy, Geographical Information Systems (GIS), statistics and data analysis, aerial imaging and remote sensing, \& nutrient and watershed management. Significant field work using various field sensors, including a chlorophyll meter, $\mathrm{pH}$ meter, and other instrumentation to measure leaf area index (LAI) in conjunction with hand held GPS units, is integrated with the course. Funds from USDA will cover at least four summer interns who will be selected from the course participants each year, while the grant is active ( 2009) to continue experiential learning and research activities initiated in spring as an integral part of the course, during the summer months.

\subsection{Introduction}

Precision Agriculture ${ }^{[1,2]}$ is a knowledge-based system that enables farmers to apply precise amounts of fertilizers, pesticides, seeds, or other inputs to specific areas where and when they are needed for optimal crop growth. It integrates many advanced engineering technologies, ${ }^{[3]}$ including GPS receivers, GIS data bases, grid sampling/mapping techniques ${ }^{[4,5]}$, yield monitors, variable-rate applications ${ }^{[6]}$ and remote sensing imagery ${ }^{[7]}$. Potentially, these advanced technologies can improve farm profitability, reduce chemical use, and reduce environmental degradation. Environmental concerns and agricultural needs are of critical importance in the rural setting of UMES and its proximity to the Chesapeake Bay.
\end{abstract}


The "Advanced Technologies in Agriculture and Environmental Sciences" has been designed as a three-credit course open to all seniors and graduate students in the Science, Technology, Engineering, and Mathematics (STEM) disciplines at UMES. The course content is delivered by two hours of lecture and 2 hours of laboratory and fieldwork per week. The course is an integral part of the USDA funded project at UMES titled "Environmentally Conscious Precision Agriculture: A Platform for Active Learning and Community Engagement".

CE

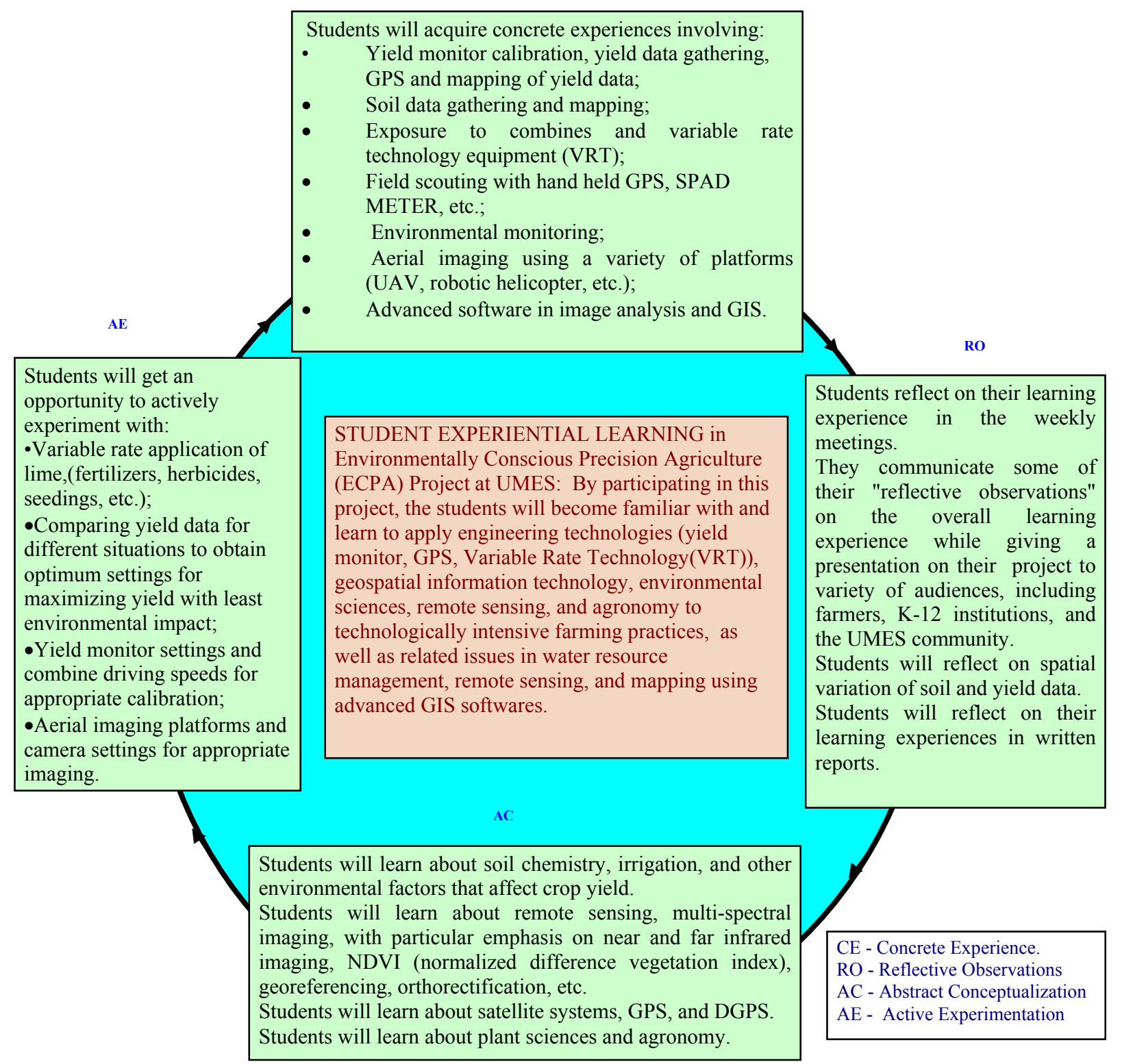

Figure 1: Kolb's Experiential Learning Cycle Adapted for the Student Experiential Learning Activity in the ECPA Project 
Experiential and active learning ${ }^{[8]}$ concepts have been incorporated in the course and the overall ECPA project. Students enrolled in the course, work through all aspects of the "Experiential Learning Cycle", including concrete experiences (CE), reflective observations (RO), abstract conceptualization (AC), and active experimentation (AE), following the framework presented in Figure 1.

2.0 Advanced Technologies in Agriculture and Environmental Sciences - Course Framework The catalog description for the course is provided below for ready reference of the readers. Advanced Technologies in Agriculture and Environmental Sciences (Credit, 3 Hours) (2 Hours Lecture +2 Hours of Lab/Fieldwork) : Computer applications involving geospatial information technology in precision crop management. Plant nutrients, Soil Fertility and Soil Sampling, Yield Monitoring, and Yield Mapping, Remote Sensing, Variable Rate Application, Sensors and geolocated information gathering, Environmental Stewardship and environmental monitoring, Data Management, Analysis and Interpretation using appropriate statistics and GIS software Prerequisite : Senior or Graduate standing in any of the STEM disciplines or permission of instructor.

The course lectures covered fundamentals of geospatial information technology (GPS and GIS) and fundamentals of "Precision Agriculture", including grid sampling, yield monitoring, variable rate technology, remote sensing, and basic statistics and data analysis. The class lectures also introduced students to plant physiology and growth stages of corn, soybeans, and wheat, as well as weed science. Students were introduced to hand-held GPS and field instrumentation for $\mathrm{pH}$ measurements ( $\mathrm{pH}$ meter), chlorophyll measurement (SPAD meter), and Leaf Area Index measurement (LAI meter). During the laboratory sessions and class lectures, aspects of ArcGIS 9.0, Matlab (Image Processing Toolbox), and EXCEL spreadsheet were covered.

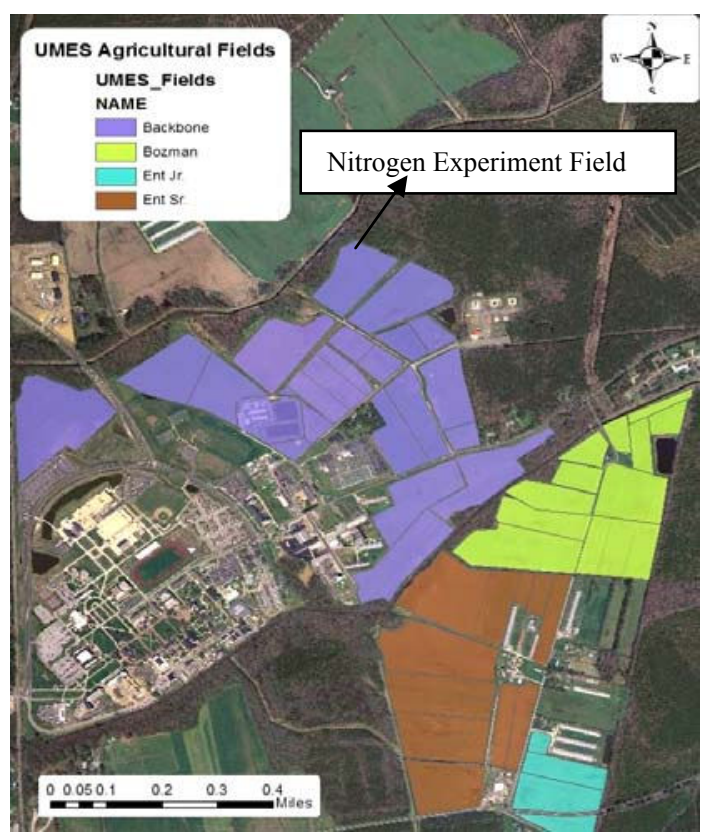

Figure 2: UMES Campus and Agricultural Fields

UMES is an 1890 Land Grant Institution. Figure 2 shows a panoramic view of the campus in which the agricultural fields have been identified. Most production fields, such as the Bozman, 
Ent (sr.), Ent (jr.), etc. at UMES grow corn, wheat, and soybeans on a rotational basis. Field experiences integrated with "Advanced Technologies in Agriculture and Environmental Science" course utilized the Bozman and a small portion of the Backbone field as shown in Figure 2.

Students worked in teams and executed two field projects involving (i) georeferenced $\mathrm{pH}$ measurements on $1 / 2$ acre grids on Bozman and (ii) the effect of varying nitrogen levels on winter wheat on the portion of Backbone field (Nitrogen Experiment Field, see Figure 2).

The field projects formed a significant aspect of the course and helped integrate measurement devices and software tools that were introduced in the course with reference to the broad field of "Precision Agriculture". The field projects are elaborated in the following sections.

\subsection{GIS Point and Raster Maps of pH Measurement on Bozman Field}

At the onset of the "Precision Agriculture" project at UMES ${ }^{[9,10]}$, the Bozman field was identified as the first one, among the UMES production fields, where some of the initial studies will be conducted to integrate "Precision Crop Management" practices at UMES without adversely impacting yield. The Bozman is a 50-acre field that grows corn, wheat, and soybean on a rotational basis. As a first step, a professional organization was hired to perform grid sampling at a $1 / 2$ acre resolution and provide soil nutrient level GIS maps for all macro and micro-nutrients relevant to crop growth. Subsequently, a "Yield Monitor" with GPS unit was retrofitted in the UMES combine and was utilized to obtain spatially distributed corn harvest data over the Bozman field. The results are documented in reference ${ }^{[10]}$. As expected, it was observed that the corn yield was strongly correlated to $\mathrm{pH}$ levels of the soil. Soil pH level of 6-6.5 is generally accepted as the optimum level for crop growth by agronomists. The initial soil tests revealed that the $\mathrm{pH}$ levels were very low (of the order of 4 and 5) on the Bozman field. In keeping with the practice of "Precision Agriculture", it was decided, instead of a uniform application of lime, a prescription GIS map based on soil $\mathrm{pH}$ levels will be developed for variable rate lime application $^{[11]}$, to bring the soil $\mathrm{pH}$ of the field around the optimal. Instead of targeting a $\mathrm{pH}$ level of $6-6.5$ throughout the Bozman field, the target $\mathrm{pH}$ levels were set according to the layout in Figure 3. Some variations around the optimal level were introduced to provide the scope for a research study by a graduate student supported by the AIRSPACES (Aerial Imaging and Remote Sensing for Precision Agriculture and Environmental Stewardship) project that involved field measurements and aerial imaging to observe crop growth characteristics due to variations in $\mathrm{pH}$ levels. In consultation with the UMES farm manager, the targeted $\mathrm{pH}$ levels were kept within the range of 5-7 so that the impact on production was not significant. The plan for precision lime application was executed in the summer of 2006 with the help of an outside vendor. Since the course was offered in the spring of 2007, this provided an ideal platform to integrate a $\mathrm{pH}$ measurement field-project using soil probes, handheld GPS units and pH meters (Figure 4). The students were divided into three teams and each team was responsible to measure about a third of the field, with one measurement for every $1 / 2$ acre grid, aligned to the original soil sampling grid layout. Figures $5 \mathrm{a}$ and $5 \mathrm{~b}$ show members of student teams collecting soil samples for this field exercise. Each team used a soil probe to take samples from 32 to 34 locations to cover the entire field and recorded the position information using a mobile GPS. Subsequently, the soil samples were processed with de-ionized water and $\mathrm{pH}$ values were obtained for each location using a $\mathrm{pH}$ meter. ArCGIS 9.0 software was used to plot these data values at appropriate locations on an 
ortho-rectified and geo-referenced base image of the Bozman farm. The point data was later converted to raster data using spatial interpolation tools embedded in ArcGIS. Students were introduced to Kriging, as well as Inverse Distance Weighting (IDW) spatial interpolation techniques ${ }^{[12]}$. Figure 6 shows the point data corresponding to $\mathrm{pH}$ measurements overlaid on spatially interpolated raster data using "Inverse Distance Weighting" technique.

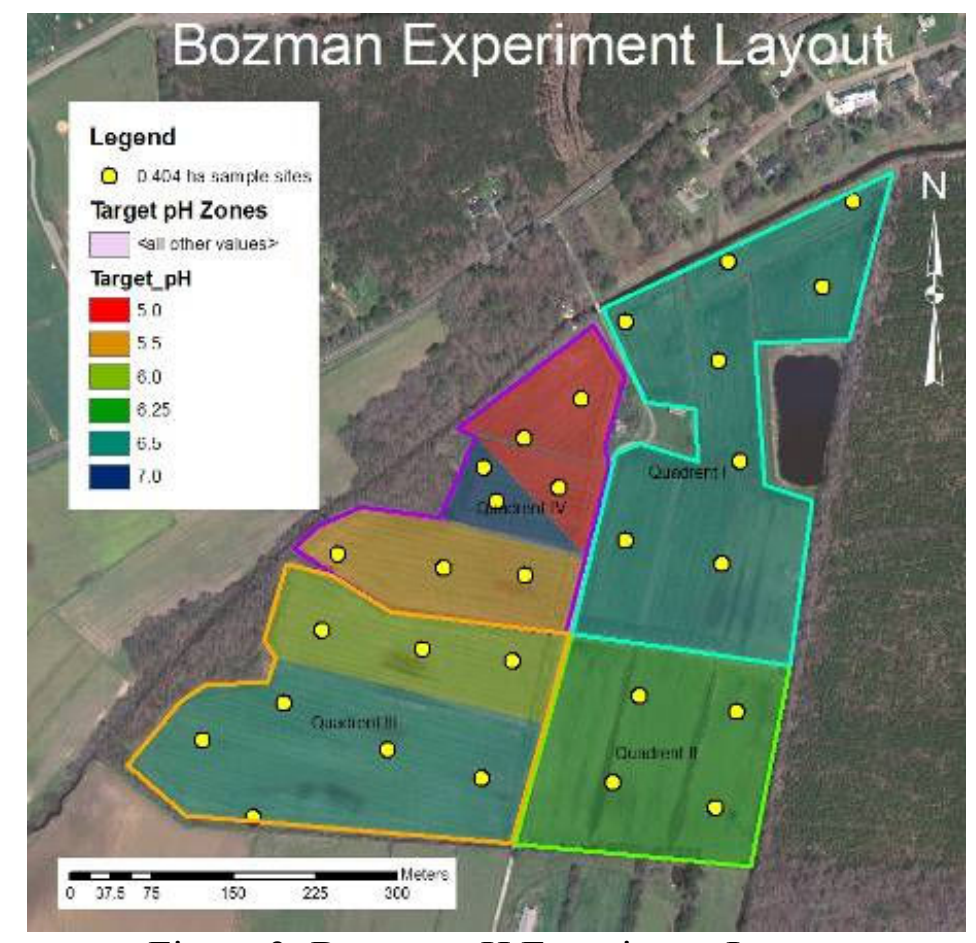

Figure 3: Bozman pH Experiment Layout
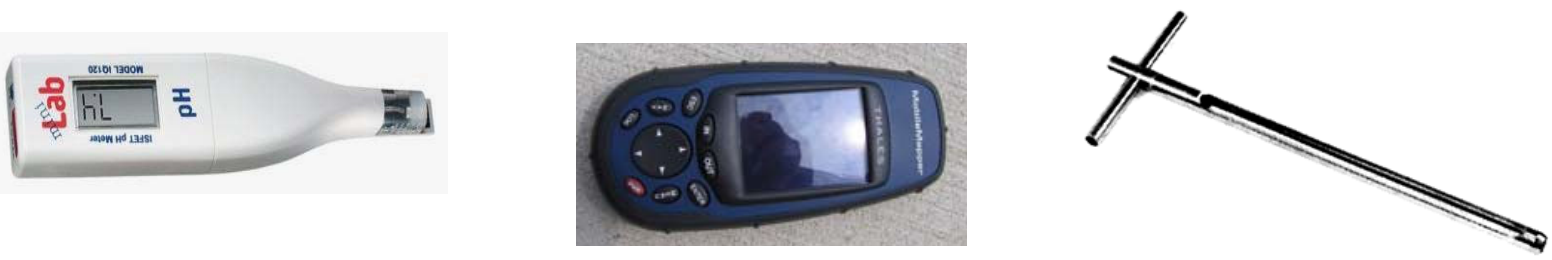

Figure 4: pH Meter, GPS Mobile Mapper, And Soil Probe

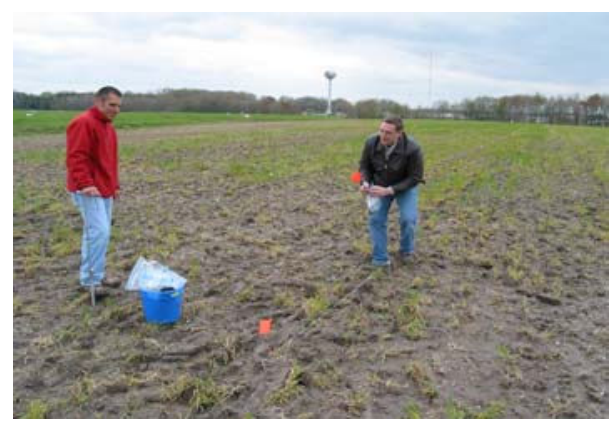

(a)

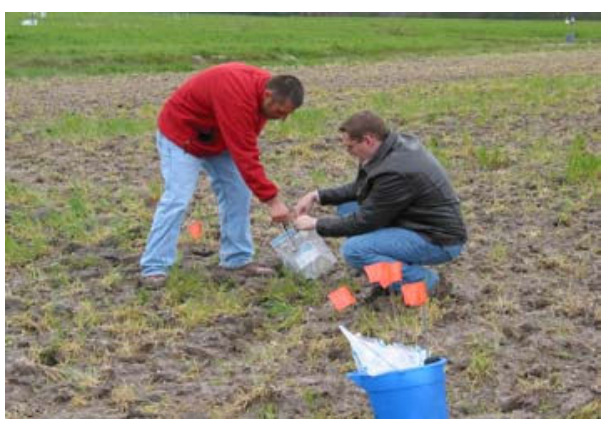

(b)

Figure 5: Student Teams Involved In Soil Sampling For $\mathrm{pH}$ Measurement 


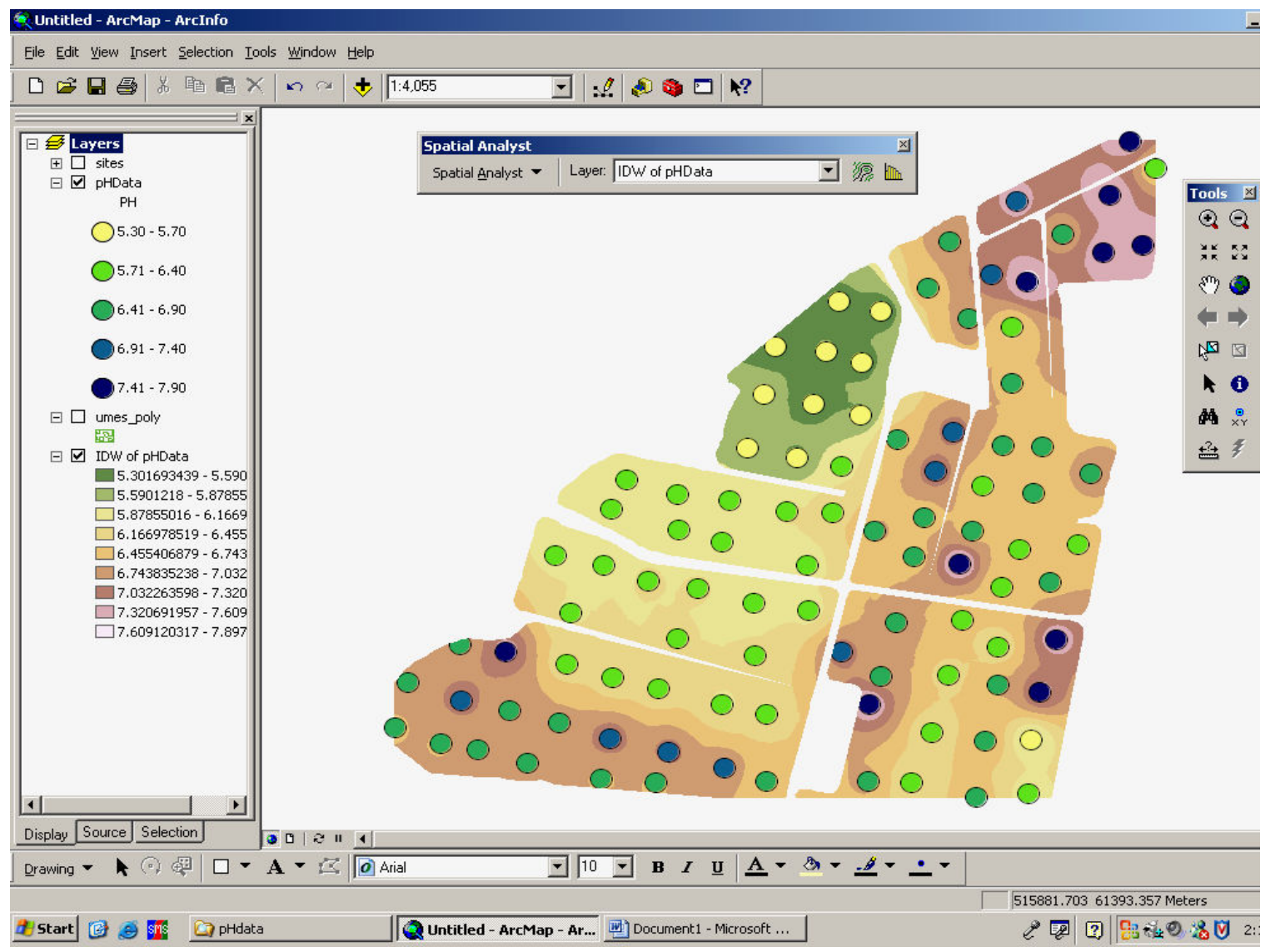

Figure 6: Point Data and Spatially Interpolated Raster Data for $\mathrm{pH}$ Measurements.

The map in Figure 6 clearly verifies that the targeted $\mathrm{pH}$ levels (by variable rate application of lime) are being gradually realized. Soil scientists and farm personnel suggest that it is a slow process, and the complete absorption of lime to impact $\mathrm{pH}$ levels can take up to two years.

The results of the field study have been subsequently correlated with corn harvest data obtained in fall/ winter 2007 for corn that was planted during summer of 2007 on Bozman field. One of the students that enrolled in the course studied effects of $\mathrm{pH}$ variation on corn using field sampling, yield monitoring, and remote sensing, for his master's thesis research under the supervision of the primary author of this paper. This student benefited from the $\mathrm{pH}$ measurement field project integrated in the course.

Moreover, the project also helped to clarify fundamental aspects of "Precision Agriculture" related to soil nutrient levels optimal for crop growth, grid soil sampling, variable rate application, and significant aspects of the use of geospatial information technology tools, including GPS, GIS, and ArCGIS 9.0/9.2 ${ }^{[13]}$ software environment for generating point data maps and raster data maps.

\subsection{Field Experiment with Wheat Plant Growth across Varying Nitrogen Levels}

With assistance from the USDA collaborator on the ECPA project, as well as the UMES farm personnel, a small portion of the Backbone field ( $\sim 5$ acres, Figure 2$)$ was selected for the 
nitrogen experiment. The plot was divided into 9 different test strips over 3 different soil types, with nitrogen application rates ranging from 0 to $200 \%(0,25 \%, 50 \%, \ldots . .200 \%)$. A $100 \%$ application rate was equal to $80 \mathrm{lb}$ N/acre surface applied as UAN (UAN is a solution of urea and ammonium nitrate in water used as a fertilizer ${ }^{[14]}$ ). The winter wheat was planted in late October and the nitrogen (UAN) application was carried out in the middle of March. Each of the nine test strips was approximately 30 feet wide and 800 feet long. A schematic layout of the experiment is shown in Figure 7. It may be noted that, for convenience of application, the percentage application does not vary uniformly. For instance, starting from the right, the first strip has $0 \%$, followed by $200 \%, 25 \%, 175 \%, 50 \%, 150 \%, 75 \%, 125 \%$, and $100 \%$ application rate based on $80 \mathrm{lb}$ N/acre of surface applied as UAN corresponding to $100 \%$. The objective of the project was to provide a field study site for the students enrolled in the course that would require them to use tools, such as a chlorophyll meter (SPAD meter, Figure 8) with a GPS unit, to record the variation in SPAD meter ${ }^{[15]}$ readings, based on nitrogen application rate in the strips, and to obtain the optimum rate of nitrogen application for the field. The set-up also provided a platform to reinforce some of the aerial imaging and remote sensing concepts related to "environmentally friendly precision agriculture" that were introduced in the course lectures.

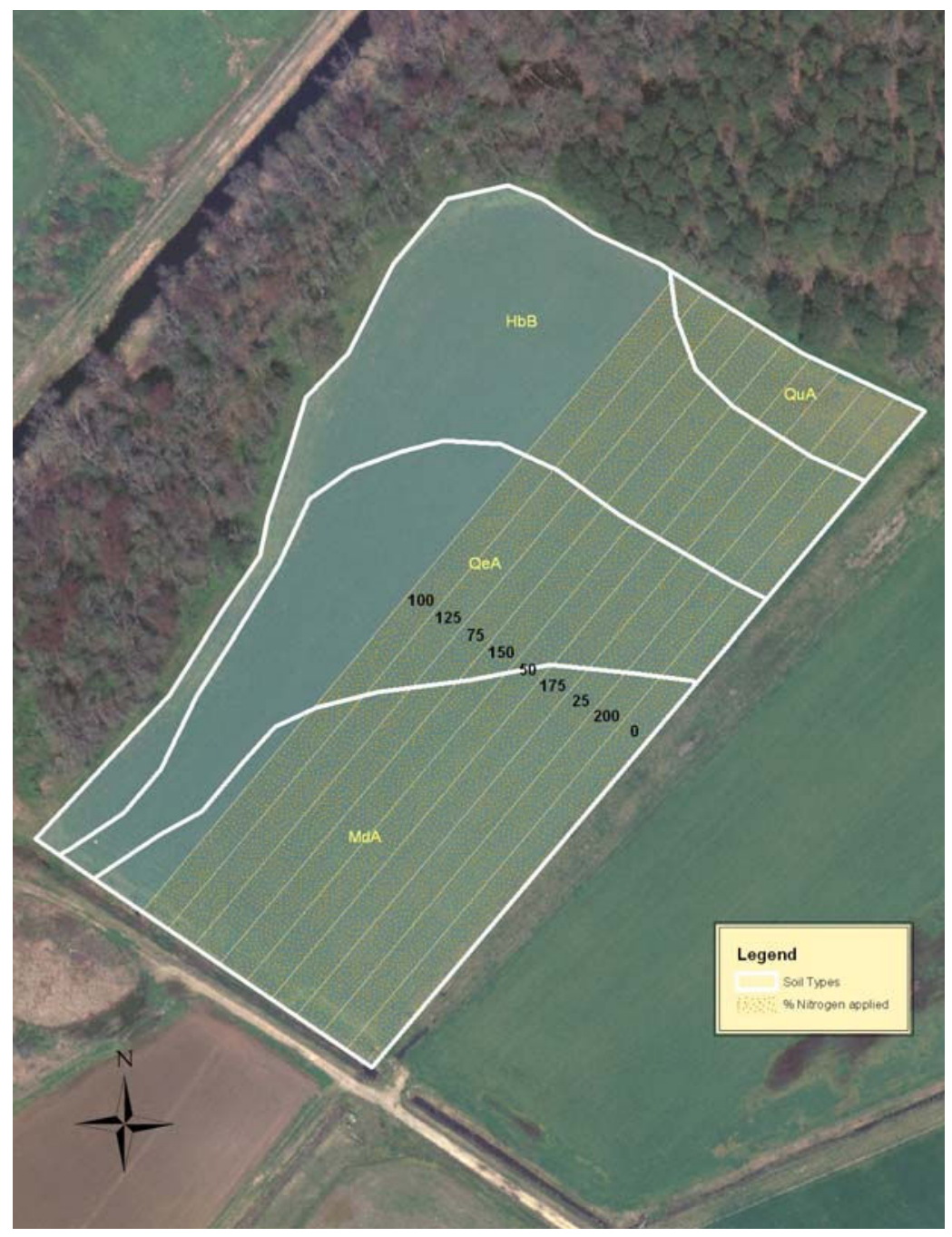

Figure 7: Experimental Layout for Varying Nitrogen Levels on Winter Wheat 


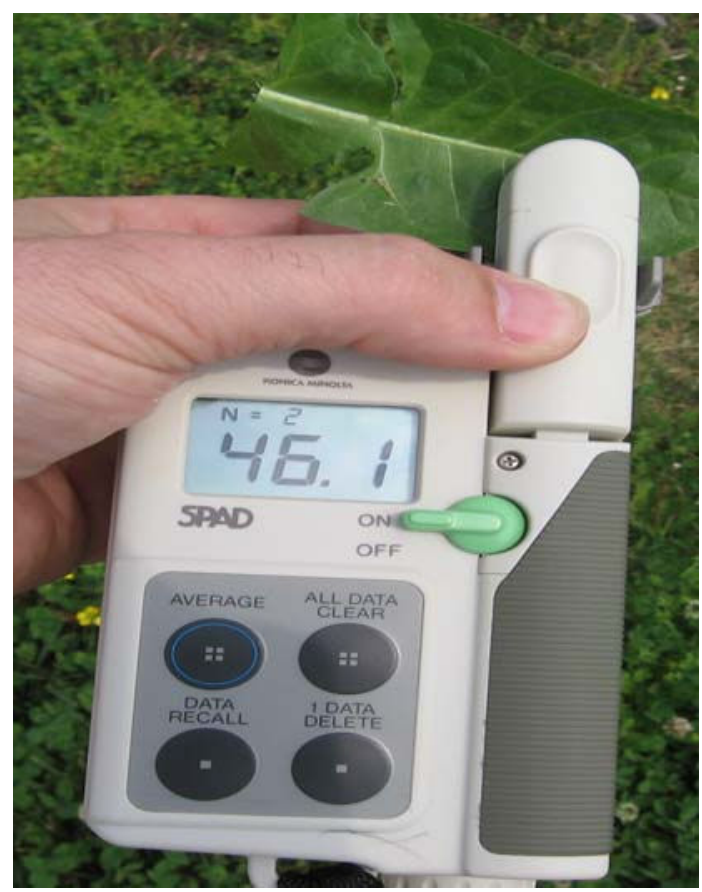

(a)

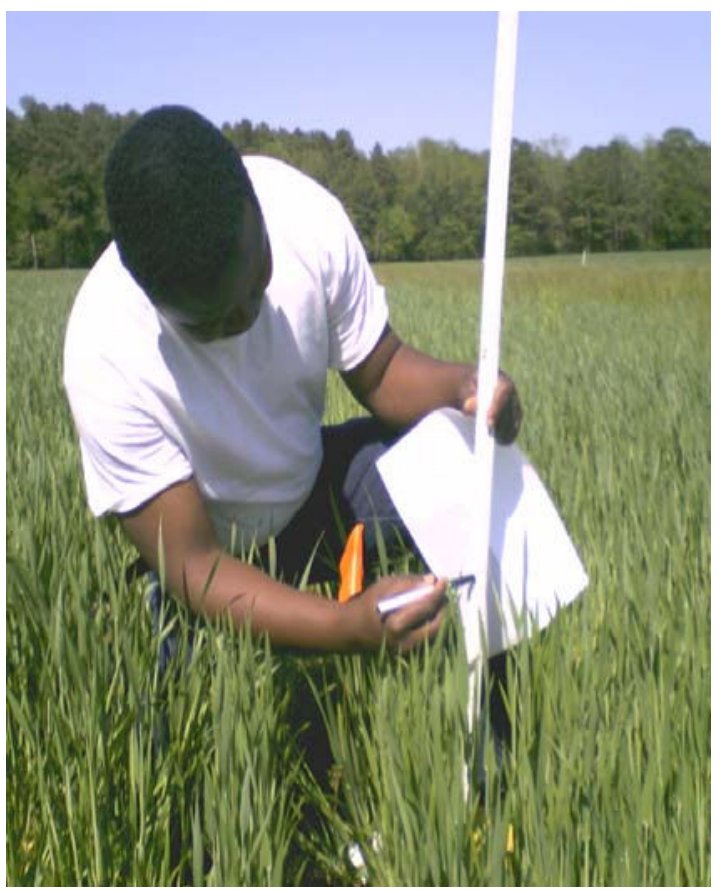

(b)

Figure 8: Students Demonstrating Use Of SPAD Meter And Measuring Plant Height In The Field

Several aerial platforms have been utilized for experiential learning and research efforts involving aerial imaging and remote sensing. They include a helium blimp with a camera payload, remote controlled model airplanes with digital camera attachment, robotic helicopter with IP camera attachment, and a manned airplane which has been retrofitted with a Terrahawk Color Infrared Digital camera system. Faculty members in the "Aviation Science" program at UMES have supported all of the aerial imaging and remote sensing efforts ${ }^{[9]}$. For aerial imaging efforts related to the nitrogen experiment the Terrahawk system ${ }^{[16]}$ was used. The system was mounted on the Cessna 172 airplane, and was piloted by an UMES Aviation Science faculty member (Figure 9).

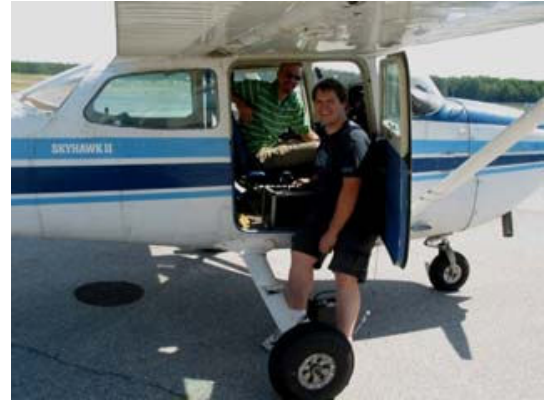

(a)

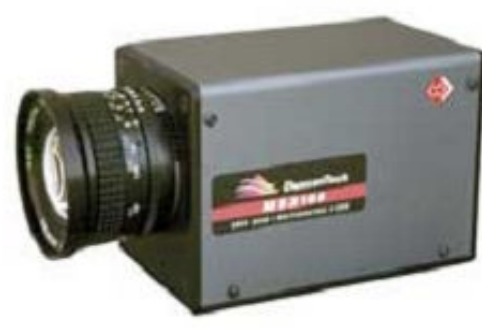

(b)

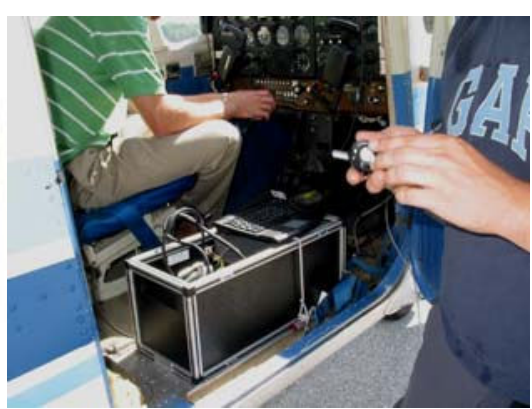

(c)

Figure 9: Cessna 172 Airplane, MS 3100 CIR and TerraHawk System mounted in Cessna 


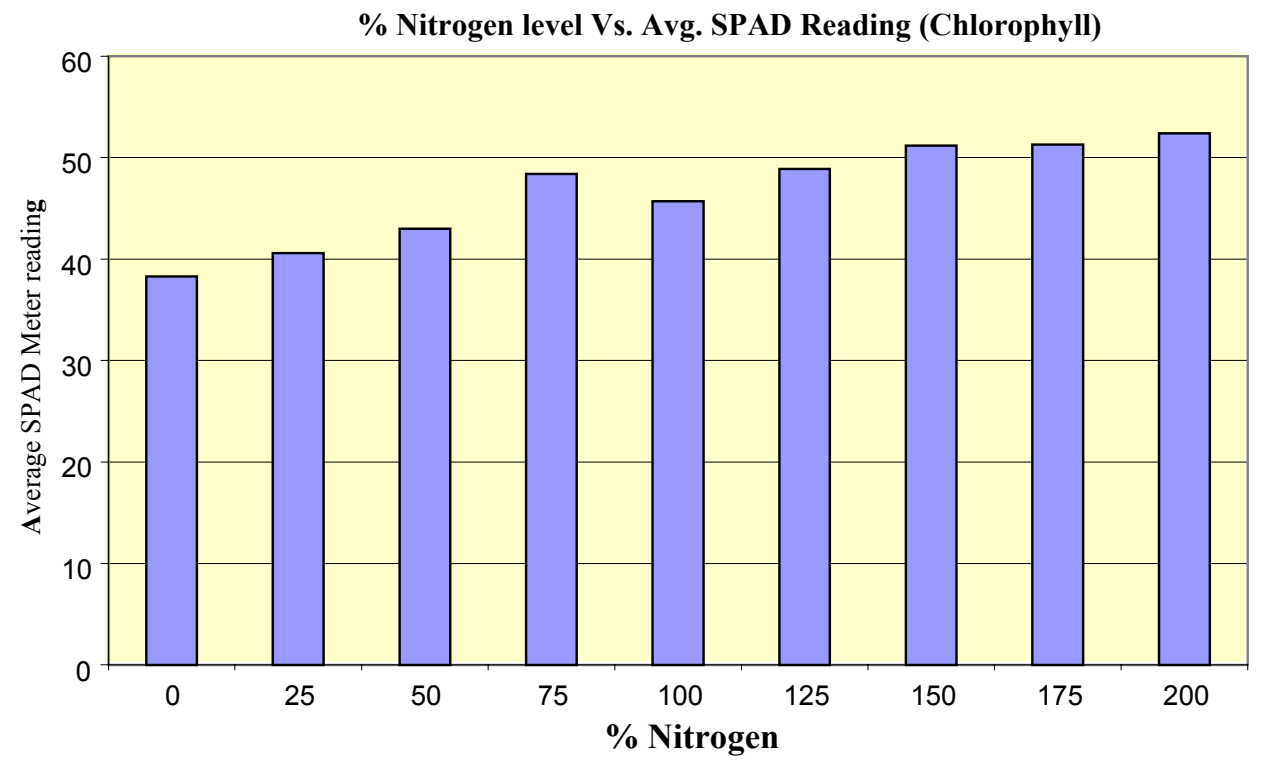

Figure 10: Bar Graph of SPAD meter readings.

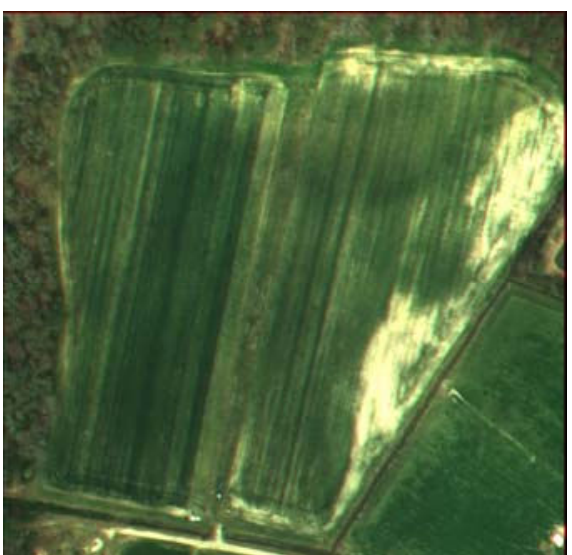

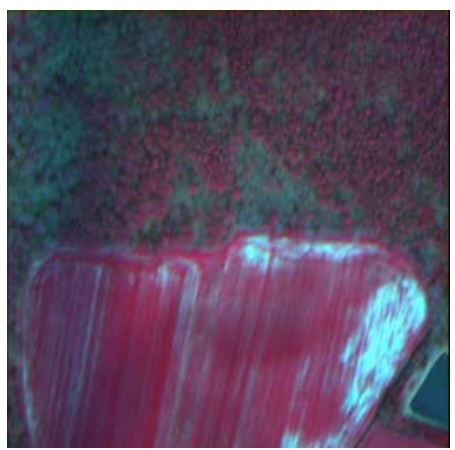

(b)

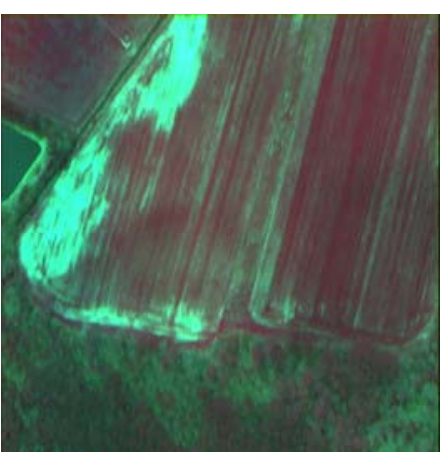

(c)

(a)

Figure 11 : (a)Wheat Experiment Field (RGB), (b,c) CIR Images Of Complementary Portions Of The Field

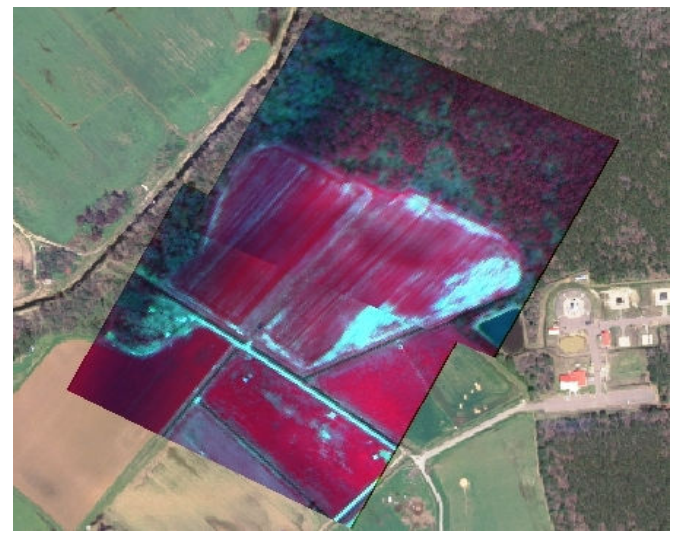

(a)

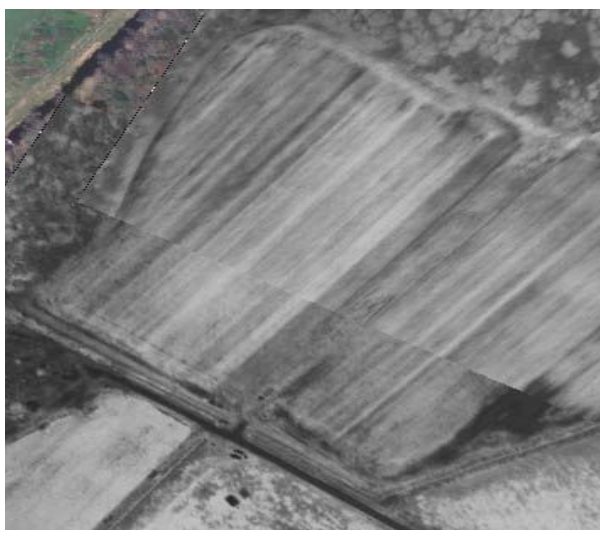

(b)

Figure 12: Mosaick View of (a) CIR Frames and (b) NDVI Frames 
As shown in Figure 7, the experimental field was divided into 9 strips with different applications of nitrogen levels. Each strip was further sectioned into 4 regions from top to bottom and appropriately flagged. The students enrolled in the class made various field measurements with a SPAD meter, LAI meter, and a ruler (for height measurements) during the crop growth period. The last field measurements were obtained in the first week of May, before the semester ended in the middle of May. Figure 10 shows a bar graph that represents the average of the SPAD meter values across the length of each strip plotted against the varying nitrogen application rates for the individual strips. It can be observed from Figure 10 that the chlorophyll levels generally increase with the increase in nitrogen application rates: however, they tend to plateau after $75 \%$ of the recommended level of $80 \mathrm{lb} \mathrm{N} /$ acre (surface applied as UAN), indicating that in this instance this would be the optimum application rate from a cost benefit consideration.

With assistance from the Aviation Science faculty at UMES, aerial images of the experimental plot were also acquired in the first week of May using the TerraHawk system ${ }^{[16]}$. Both RGB and CIR (Color InfraRed) images of the plot were captured from the Cessna 172 flying at a height of $500 \mathrm{ft}$. As shown in Figure 11(a), a single RGB frame enveloped the entire experimental field: however, due to slower frame capture rate it took two overlapping CIR frames (Figures $11 \mathrm{~b}$ and 11c) to capture the area of interest. These frames were subsequently digitally stitched (mosaicked), rectified, and georeferenced to obtain a CIR image of the entire plot (Figure 12 (a)). Also, using the pixel intensities in the near infrared and red bands in the CIR frames, normalized difference vegetation index (NDVI) images ${ }^{[17]}$ were obtained using Equation 1:

$$
\mathrm{NDVI}=(\mathrm{NIR}-\mathrm{RED}) /(\mathrm{NIR}+\mathrm{RED})
$$

where RED and NIR are reflectance values for the red and near infrared bands of the Terrahawk digital camera.

NDVI frames were digitally stitched, rectified and georeferenced to obtain Figure 12 (b). NDVI and other vegetation indices derived from multi-spectral images play a critical role in precision agriculture. Among other applications they have been used for yield prediction, as well as, geolocating, detecting crop health, and taking early preventive measures.

The students learned basic features of the "Image Processing Toolbox" of Matlab software for NDVI analysis. ArcGIS 9.0 was used for rectification, georeferencing, and mosaicking aspects. Also the students readily realized the relevance of remote sensing and geospatial information technology for agricultural applications. The effects of the variable nitrogen application rate on the strips can be clearly observed from RGB, CIR, and NDVI images of the experimental plot. Preliminary investigations were done to correlate average pixel intensities across the test strips with the SPAD meter data, but due to time limitation, this aspect could not be completed.

At the end of the spring semester, three of the students enrolled in the course, who performed well and showed interest were offered summer internships to continue to work on the project. Among other efforts, the summer interns were assigned to work with the farm personnel to harvest the wheat using "Yield Monitor". One of the students also collected samples of wheat grain from each of the nine test strips and estimated the protein content using facilities in the 
"Food Science Laboratory" at UMES. The results of wheat yield against the nitrogen application rate levels and of percentage protein content against the applied nitrogen level are shown in Figures 13 and 14.

\section{Wheat Yield Vs. \% Nitrogen Level}

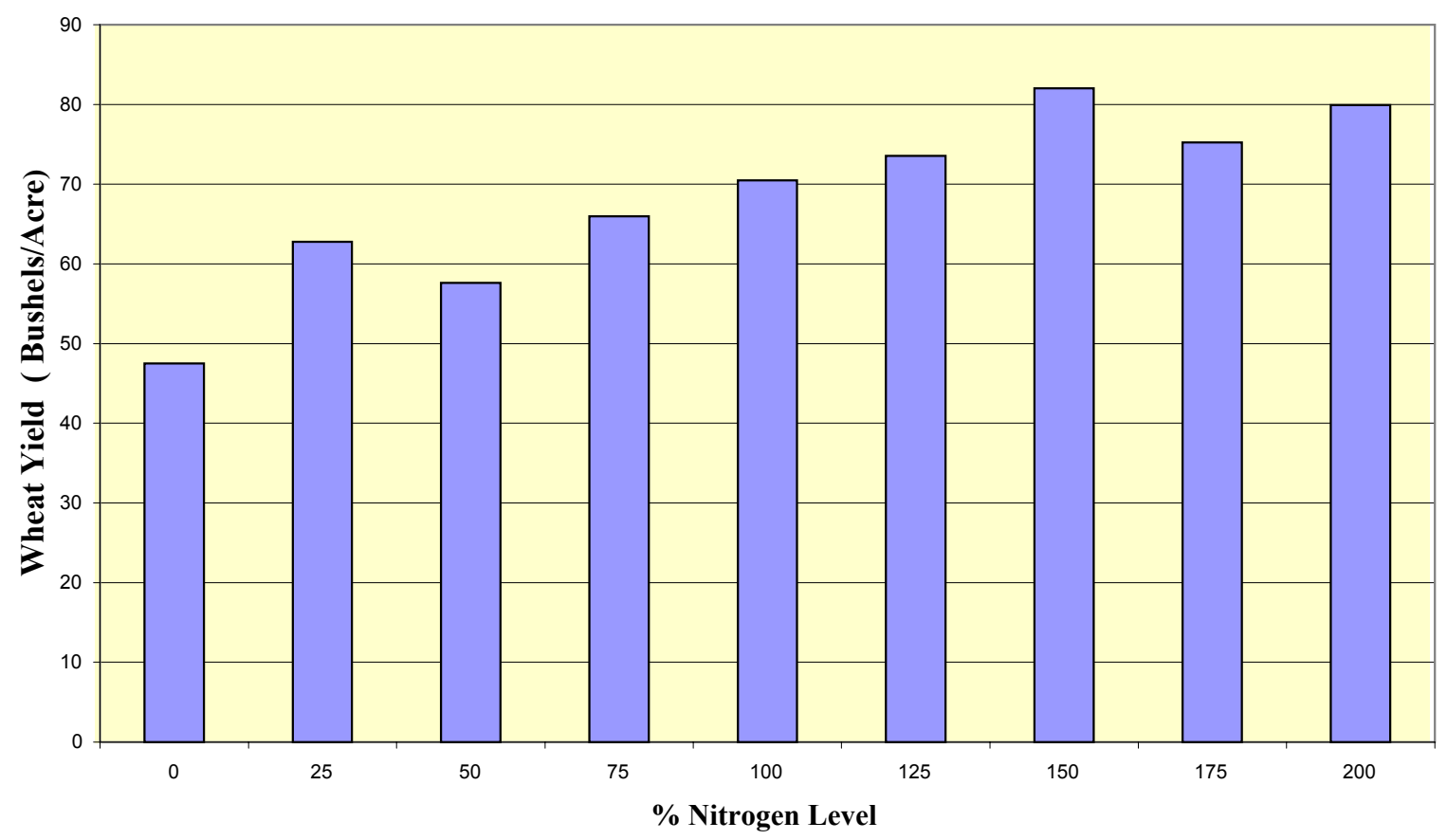

Figure 13: Wheat Harvest Data

Nitrogen Level Vs. Protein Content

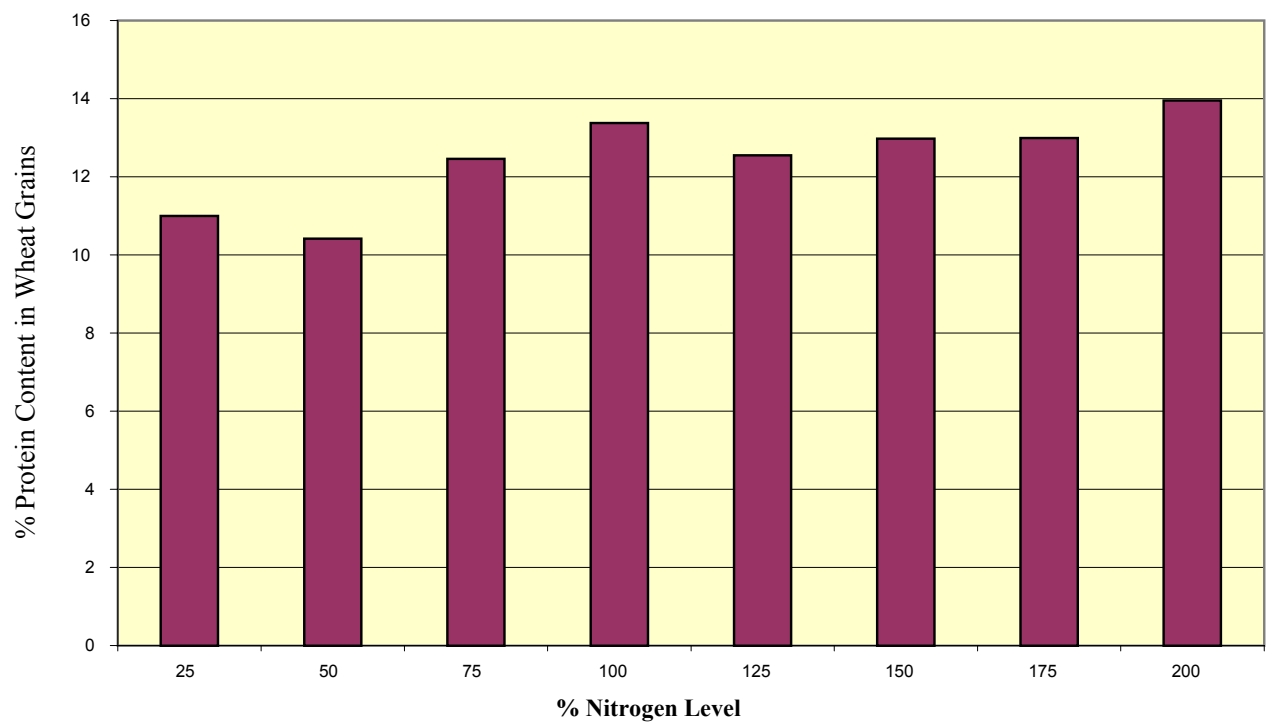

Figure 14: Protein Analysis Results 


\subsection{Conclusion}

The pilot run of the course went well. The student feedback has been very good. The only suggestion they have provided is that the field work component should be spread throughout the semester instead of just in the last four weeks. In structuring the lecture, software exercises, and field work components in the course, the faculty and staff team who designed the course had taken into consideration severity of cold temperature, constraints associated with the planting and growth of winter wheat, student knowledge base, and other factors; but since the students felt overworked towards the end of the semester, the faculty team has decided to modify the structure in accordance with the student feedback. Instead of clustering all the fieldwork towards the end of the semester, in the next run of the course it will be spread throughout the semester.

\subsection{Acknowledgment}

The authors would like to thank all the UMES farm personnel who helped with the fieldwork, as well as all the students who enrolled in the course, and encountered some of the uncertainties with the pilot run and the nontraditional team-taught structure of the course. Mr. Gabriel Ladd, Mr. Frederick Ketterer, Mr. Bryan Burrows-McElwain, Mr. Henry Xavier, Ms. Leslie Bensinger and Mr. Otto Schlicht were the seniors and graduate students spread across the STEM majors at UMES who braved the first offering of the course. Mr. Henry Xavier, Mr. Gabriel Ladd, and Ms. Leslie Bensinger continued to work in the project over the summer as research assistants and summer interns. The authors would also like to acknowledge the USDA/CSREES grant titled "Environmentally Conscious Precision Agriculture (ECPA): A Platform for Active Learning and Community Engagement" that provided funds for the summer interns, as well as to develop the course and the field projects. The authors would like also like to thank Mr. Christopher Hartman (Lecturer, Aviation Science Program) for the piloting efforts, and, the Maryland Space Grant Consortium for the funding of "AIRSPACES : Aerial Imaging and Remote Sensing for Precision Agriculture and Environmental Stewardship" project. The synergy between the AIRSPACES and ECPA projects has helped in advancing the "remote sensing" and "precision agriculture" related efforts on the UMES campus.

\section{Bibliography}

1. Lu, Y., Daughtry, C., Hart, G., and Watkins, B., 1997, “The Current State of Precision Farming", Food Rev. Int. 13(2), 141-162

2. Pfister, B., 1998, What is Precision Agriculture?, Available Online @ http://www.directionsmag.com/article.php?article id $=31$

3. Sudduth, K.A., "Engineering Technologies for Precision Farming", Presented at the International Seminar on Agricultural Mechanization Technology for Precision Farming, Suwon, Korea, May 17, 1999. Available Online@ @ http://www.fse.missouri.edu/mpac/pubs/eng tech.pdf

4. Rao, S.M. and W.D., Lee, 2002. UF/IFAS Nutrient Management Series: Soil Sampling Strategies for Precision Agriculture, Document \# SL 190, Available Online @ http://edis.ifas.ufl.edu 
5. Slater, B., 2000. Principles of Soil Sampling for Precision Farming, Ohio State University Extension (C) 2000 Available Online @ http://precision.ag.ohio-state.edu/ precisfm/library/

6. Clark, R.L., and McGuckin, R.L.,1996 "Variable Rate Application Equipment for Precision Farming" Presented at 1996 Beltwide Cotton Conference, Nashville, Jan 96, Available Online : http://www.engr.uga.edu/research/groups/precisionfarming/clark_vrt.html

7. Jurgens, C., 1997. The modified normalized difference vegetation index (NDVI)-a new index to determine frost damages in agriculture based on Landsat TM data. International Journal of Remote Sensing, 18(17):3583-3594.

8. Kolb, D.A., 1984 "Experiential Learning: Experience as the Source of Learning and Development, Englewood Cliffs, NJ.: Prentice Hall, 1984.

9. Nagchaudhuri, A., Mitra, M., Brooks, C., Earl, T.J., Ladd, G., and Bland, G., "Integration of Mechatronics, Geospatial Information Technology, and Remote Sensing in Agriculture and Environmental Stewardship", Proceedings of 2006 International Mechanical Engineering Congress and Exposition (IMECE'06), , November 5-10, Chicago, IL., 2006

10. Nagchaudhuri, A., Mitra, M., Brooks, C., Earl, T.J., Ladd, G., Conry, R., and Bland, G., "Initiating Environmentally Conscious Precision Agriculture at UMES", Proceedings of 2005 ASEE Annual Conference, June 12-15, Portland, Oregon, CD ROM

11. Fulton, J.P., S.A. Shearer, G. Chabra, and S.F. Higgins. 2001. Performance assessment and model development of a variable-rate, spinner fertilizer disc applicator. Transactions of ASAE (American Society for Agricultural Engineers) Vol. 44(5): 1071-1081.

12. Robinson, T.P., and Metternicht, G., "Testing the Performance of Spatial Interpolation Techniques for Mapping Soil Properties," Computers and Electronics in Agriculture Volume 50, Issue 2, February 2006, Pages 97-108

13. ArcGIS 9.0/9.2: http://www.esri.com/software/arcgis/index.html

14. UAN (solution of urea and ammonium nitrate) : http://en.wikipedia.org/wiki/UAN

15. Minolta SPAD 502 Meter: http://www.specmeters.com/Chlorophyll_Meters/Minolta_SPAD_502_Meter.html

16. Terra Hawk Aerial System, http://www.terraverdetech.com/Brochures/TerraHawk.pdf

17. Perry, E.M., and Davenport, J.R., "Spectral and spatial differences in response of vegetation indices to nitrogen treatments in apple" Computers and Electronics in Agriculture, Vol. 59, Issues 1-2, pp 56-65, November 2007. 